\title{
Alireza Askari Chaverdi, Pierfrancesco Callieri. Persepolis West (Fars, Iran). Report on the field work carried out by the Iranian-Italian joint Archaeological Mission in 2008-2009
}

\section{Rémy Boucharlat}

\section{(2) OpenEdition}

\section{Journals}

Édition électronique

URL : http://journals.openedition.org/abstractairanica/48276

DOI : $10.4000 /$ abstractairanica.48276

ISBN : 1961-960X

ISSN : 1961-960X

Éditeur :

CNRS (UMR 7528 Mondes iraniens et indiens), Éditions de l'IFRI

\section{Référence électronique}

Rémy Boucharlat, «Alireza Askari Chaverdi, Pierfrancesco Callieri. Persepolis West (Fars, Iran). Report on the field work carried out by the Iranian-Italian joint Archaeological Mission in 2008-2009 ", Abstracta Iranica [En ligne], Volume 40-41 | 2019, document 23, mis en ligne le 15 juillet 2019, consulté le 19 avril 2021. URL : http://journals.openedition.org/abstractairanica/48276 ; DOI : https://doi.org/10.4000/ abstractairanica.48276

Ce document a été généré automatiquement le 19 avril 2021.

Tous droits réservés 


\title{
Alireza Askari Chaverdi, Pierfrancesco Callieri. Persepolis West (Fars, Iran). Report on the field work carried out by the Iranian-Italian joint Archaeological Mission in 2008-2009
}

\author{
Rémy Boucharlat
}

\section{RÉFÉRENCE}

Alireza Askari Chaverdi, Pierfrancesco Callieri. Persepolis West (Fars, Iran). Report on the field work carried out by the Iranian-Italian joint Archaeological Mission in 2008-2009. Oxford: BAR International Series 2870, 2017, 293 p., ill.

1 Ce volume est le deuxième de la série consacrée aux résultats de la première phase du programme conjoint irano-italien From the palace to town, sur la conservation des vestiges et la recherche à Persépolis, sur la terrasse et aux alentours de celle-ci. Ce volume rend compte des sondages stratigraphiques menés sur Persépolis $\mathrm{W}$, zone ainsi nommée depuis les prospections de W. Sumner dans les années 1970. C'est l'espace entre $500 \mathrm{~m}$ et $1500 \mathrm{~m}$ à l'ouest de la terrasse. En surface, parsemée de petits monticules supposés correspondre à des constructions, les tessons de poterie, assez peu nombreux, appartiennent à la catégorie de poterie traditionnellement attribuée à l'époque achéménide (et plus tard). Dans ce secteur et plus généralement dans la plaine proche de la terrasse, on tente de retrouver ce qui aurait été la ville de Persépolis dont la terrasse ne porte qu'une partie du quartier royal.

2 L'emplacement des sondages conduits en 2008 et 2009 a été déterminé par les résultats des prospections géophysiques (méthode magnétique) conduites au cours les années précédentes. Celles-ci révélaient des « anomalies » correspondant à des structures en 
creux (fossés, canaux) ou structures pleines, comme les murs ou éventuellement des fours et des foyers.

Dans ce secteur, gravement bouleversé par les travaux agricoles mécanisés des dernières décennies, les prospections géophysiques ont révélé une grille orthogonale de cellules aux dimensions variables; les figures linéaires correspondraient à des canaux, drains et rigoles (voir pp. 4-25 et voir la carte synthétique fig. 20). Les sondages archéologiques ont confirmé cette hypothèse. Selon les archéologues, Persépolis West et par extension toute la région bien au-delà, ne seraient pas densément bâties, à la différence de la plupart des villes orientales antérieures, mais correspondraient à une mosaïque de zones construites et non construites, dans tous les cas aménagées. Cet aménagement des paysages (landscaped sectors) rappelle celui de Pasargades (cf. Benech, Boucharlat, Gondet, AbsIr 34-36, no. 76).

Après cette présentation, suivent les rapports détaillés et abondamment illustrés des 11 sondages, en général très réduits ( $4 \times 4 \mathrm{~m}$, parfois le double), menés dans l'ensemble de la zone (chap. 2. pp. 26-106). Les structures découvertes sont très modestes, mais on note un four et, autour de celui-ci des petites fosses contenant des fragments d'ossements. Or, les os constituent le principal composant de la fluorapatite, une substance qui a servi à blanchir la surface des monuments de Persépolis, éléments d'architecture et reliefs.

Dans le chap. 3, plusieurs auteurs traitent de la céramique, ainsi que des autres objets : des remarques sur la méthode de traitement de la céramique, des observations sur les caractéristiques techniques et sur les formes diagnostiques, en particulier sur les bols et coupes, dont certaines formes caractéristiques sont datées de l'époque achéménide dans le Fars et dans beaucoup de régions de l'empire (Table 14). Les "Tables and Plates » de deux des sondages 4 et 6) constituent un catalogue analytique de la poterie. Le chapitre 4 "Radiometric datings » apportent finalement peu de données précises, mais il faut rappeler que pour la première moitié du $1^{\mathrm{er}}$ millénaire av.n.è. la méthode radiocarbone souffre de l' "effet plateau» perturbant gravement les datations. Espérons que les travaux à venir donneront une vue plus synthétique de la production de cette époque que les sondages très réduits et dispersés sur Persépolis $\mathrm{W}$ pouvaient difficilement fournir. De ce point de vue, comme au plan de la vision à reconstruire autour de la terrasse Persépolis, les travaux menés constituent une très utile étape préliminaire.

\section{AUTEURS}

\section{RÉMY BOUCHARLAT}

UMR 5133 CNRS-Université de Lyon 